\title{
MUJERES CERAMISTAS CONTEMPORÁNEAS. EL CASO DEL MUSEO DE ARTE CONTEMPORÁNEO VICENTE AGUILERA CERNI DE VILAFAMÉS (CASTELLÓN)
}

\author{
WOMEN CONTEMPORARY CERAMISTS. THE CASE OF THE CONTEMPORARY ART MUSEUM
}

VICENTE AGUILERA CERNI FROM VILAFAMÉS (CASTELLÓN)

\author{
Esther Astarloa \\ Ceramista. Arte Eskola de Deba (Guipuzcoa)
}

RESUMEN

El presente trabajo propone una reflexión en torno a la cerámica contemporánea, poniendo especial atención en las mujeres ceramistas y en su presencia en un concreto centro artístico, el Museo de Arte Contemporáneo Vicente Aguilera Cerni de Vilafamés (Castellón). En primer lugar, se consideran algunos aspectos y antecedentes que ayudan a contextualizar y situar el tema y posteriormente se reúne la información sobre el objeto de estudio, centrándonos en el análisis de la colección cerámica que alberga el Museo, junto a la trayectoria y características de sus autoras/es. La perspectiva feminista está presente en todo momento, pues se parte de la premisa de que las desigualdades de género siguen patentes en la sociedad y también en el ámbito cerámico (pese a la presencia que aquí tienen las mujeres).

Palabras clave: Mujeres ceramistas, cerámica contemporánea, arte-artesanía, MACVAC, perspectiva de género.

\section{ABSTRACT}

The present work proposes a reflexion about contemporary ceramic art focusing on female artists and their presence in a specific artistic centre, "Museo de Arte Contemporáneo Vicente Aguilera Cerni de Vilafamés» (Castellón). Firstly, backgrounds and aspects that help place the subject are taken into account and then information about the object of the study is gathered, which is concentrated on the analysis of the ceramic collection held by the museum along with its authors' trayectory and characteristics. The feminist perspective is present throughout the study as the assumption that gender disparity is still patent in society and in the ceramic field (despite a great presence of women).

Keywords: Women Ceramist, Contemporary Ceramic, Art-Handcrafts, MACVAC, Gender perspective.

\section{SUMARIO}

1.- Introducción. 2.- Cerámica y género. 3- Invisibilización. La escasa presencia cerámica en los espacios artísticos. 4.- Panorama actual, las/os ceramistas y sus obras. 5.- El caso del Museo Vicente Aguilera 


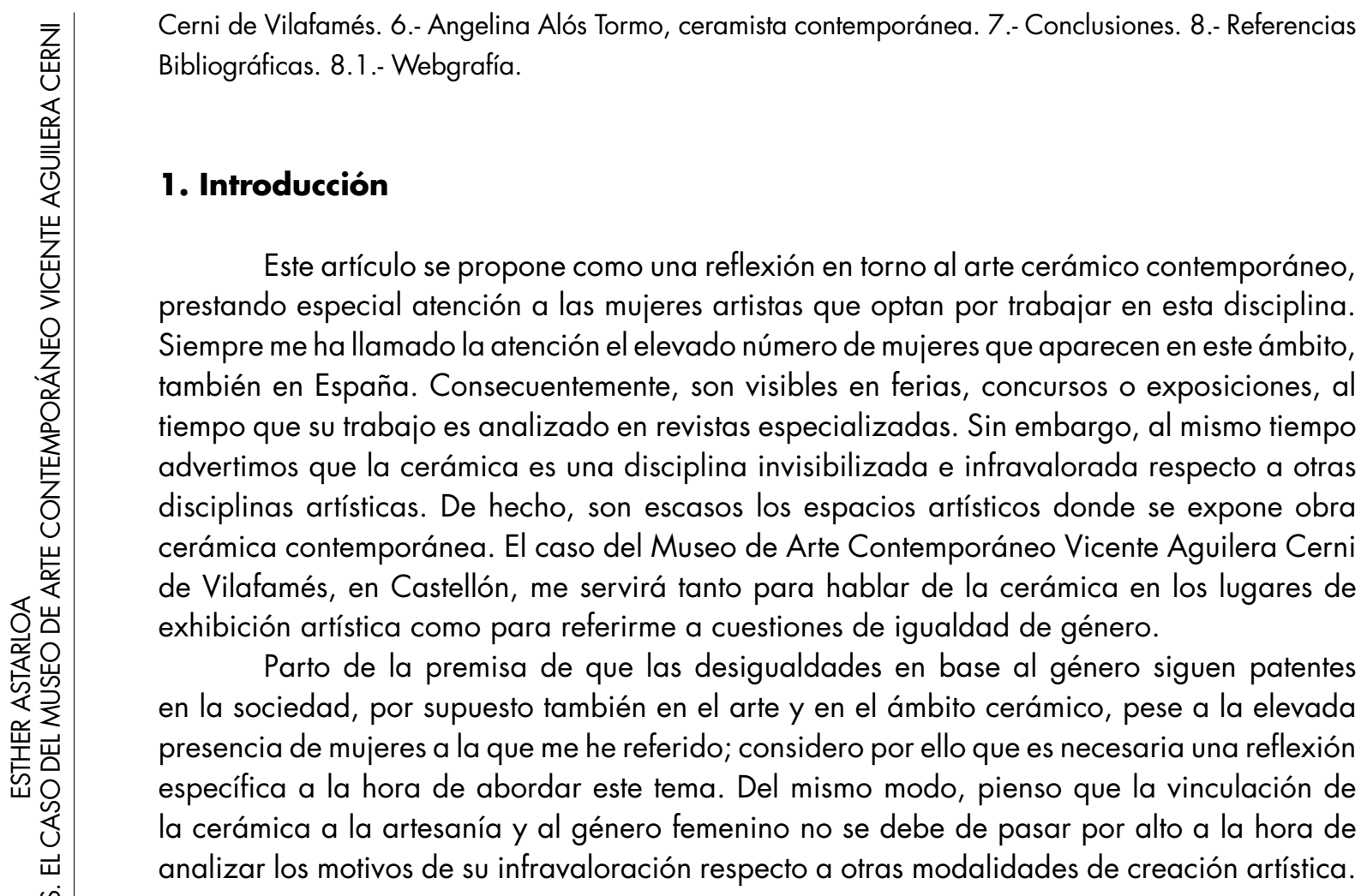

\section{Cerámica y género}

Podemos decir que existe una relación histórica entre cerámica y género. Es una actividad que tradicionalmente se relaciona con las mujeres (aunque solo sea por el uso funcional que hacen de ella en los hogares). Si ellas la utilizaban, también podrían ser sus artífices, siendo ésta quizá una de las causas de que se encuentre infravalorada. Habitualmente, la cerámica se sigue identificando con la alfarería y por ello se entiende como artesanía, con lo que se le asigna automáticamente una categoría inferior, ya que podemos afirmar que hoy se sigue asumiendo la artesanía como elemento menor en relación al arte. Estas asociaciones, en un principio parece que no tengan nada que ver con el género, sin embargo, sabemos que la sociedad patriarcal históricamente ha asignado a la mujer el espacio privado y los roles de reproducción y cuidados, vinculándola con la naturaleza; al hombre, por el contrario, se 
le ha asignado el espacio público, la política, educación, economía....relacionándolo con lo mental. La artesanía mayoritariamente produce objetos que responden a necesidades fisiológicas, y en este sentido supone una extensión de los cuidados, probablemente razón por la cual se percibe como algo afín a las mujeres. El caso de la alfarería es un claro ejemplo. Sin embargo, el arte, en cuanto a respuesta a una necesidad mental, habitualmente es considerado propio del hombre. En lo referente a la distinción entre arte y artesanía, cabe señalar un remoto precedente en la Grecia Clásica, con su diferenciación entre episteme y tekné, esto es, entre conocimiento filosófico y prácticas manuales. En el Renacimiento, se vincula el arte a la idea y la artesanía a la técnica, surgiendo en este contexto la idea del «artista-genio». Nos percatamos de que este tipo de asociaciones, asumidas a lo largo del tiempo, logran sutilmente grabar en nuestro imaginario diferencias de género y en este caso también las que atañen a lo que entendemos por lo que es el arte y el ser artista. De acuerdo con la antropóloga norteamericana Prudence M. Rice:

Entre estas actitudes peyorativas encontramos un conjunto de creencias simplistas estereotipadas sobre los orígenes y la práctica tradicionalmente doméstica de la alfarería y la asociación entre mujeres y objetos cerámicos. La elaboración de vasos se considera habitualmente un «trabajo de mujeres» y las funciones del trabajo femenino y de las actividades domésticas han sido durante largo tiempo ignoradas e infravaloradas en los estudios económicos e históricos (1999: 215).

En España, en cuanto a producción cerámica se refiere, observamos algunos estudios que prestan especial atención a las mujeres alfareras por su importante presencia en dicho oficio a lo largo de la historia. Según la doctora María Victoria Yepes Sanchidrián, la producción femenina se centra en lo básico y funcional para uso doméstico, en su mayoría vasijas. Las alfareras, ajenas por lo general a una dedicación exclusiva e integrada en la economía tradicional doméstica, suelen limitar su producción a determinados periodos del año, y en ocasiones sujetas a supersticiones y ritos. A diferencia de los alfares de organización y estructura gremial sostenidos por los hombres, con maestros, aprendices, etc... la mujer no dispone de un obrador en su taller y su producción se realiza al aire libre la la puerta de sus viviendas, bajo los hórreos, en patios y corrales) (Cifr. en Yepes Sanchidrián, 1987: 467484). Contamos también con el interesante trabajo de llse Schütz quien subraya la necesidad de prestar atención tanto a las tareas consideradas principales como a las consideradas auxiliares y a la distribución del trabajo por sexo en los estudios sobre alfarería:

En mis visitas a estas mujeres que aún perduran en España, me he encontrado con cosas muy interesantes. En Pereruela (Zamora) por ejemplo, ocurre que los hornos son de propiedad 
particular y el técnico de la cocción es el hombre. La alfarera que no dispone de horno propio con su hombre para efectuar la cocción tiene que vender su obra en crudo, porque en los hornos no se admite género ajeno al propietario (Schültz: 1993: 11).

Estos trabajos nos revelan las características y circunstancias de estas mujeres (en las cuales advertimos claramente aspectos de discriminación de génerol y nos ayudan a conocer la historia de la producción cerámica:

En plena década de los noventa parece ya incuestionable la evolución que el sentido de la mayor parte de obra alfarera ha experimentado desde una función fundamentalmente utilitaria hasta una meramente decorativa. Esta inversión de prioridades en la obra alfarera que han traído los nuevos tiempos ha hecho que a veces el recipiente de barro sea un simple soporte material para la labor decorativa. Pese a que en algunos centros esta área es exclusiva de las manos femeninas, no se ha dado un cambio parejo en la consideración de la autoría de la pieza, de modo que cualquiera que sea el grado de participación de la mujer en las distintas fases del proceso alfarero e incluso aunque su papel sea preponderante en la decoración y ello le confiera el interés comercial a la pieza, la obra final es considerada siempre resultado del trabajo masculino y será el hombre el que la firme si es que la obra va así diferenciada. Las propias decoradoras suelen restar importancia a su labor y considerar que no es equiparable al buen hacer del torneado (Alba y Fernández: 1993: 03).

En este sentido se expresan Bernárdez, Fernández y López Cao, que nos muestran cómo, desde los orígenes de la humanidad las mujeres han estado implicadas en la elaboración de las piezas de alfarería, siendo responsables de que se cambiaran los hábitos alimenticios, lo que les haría progresar muchísimo en los índices de la esperanza de vida. Por otro lado, señalan que la cerámica ha tenido gran plasticidad como sistema de comunicación y soporte de información de gran persistencia y durabilidad a lo largo del tiempo y las culturas pues ha permitido leer en ella las primeras escrituras, los primeros esbozos artísticos o las primeras narraciones míticas que los pueblos han ido creando para explicarse a sí mismos. Mientras que otras formas de guardar información a través de la escritura o la pintura realizada sobre papiro, pergamino o papel eran objetos que pertenecían a las élites sociales, la expresión de la pintura o los decorados sobre cerámica, han sido forma de expresión para todas las clases sociales y todos los géneros. Utilizada para lo refinado y lo vulgar, lo útil y lo inútil, lo decorativo y lo práctico. En esta ocasión sí percibimos claramente una propuesta dirigida a superar las desigualdades de género mediante un acercamiento crítico a la historia y teoría del arte, ya que nos da pie a reflexionar sobre la vida de las mujeres, sus formas de producir arte y manufacturar objetos y ello ayuda a que las mujeres se reconozcan como parte activa y creadora de la sociedad y de su patrimonio socio cultural. El caso de la alfarería no es único, 
pero sí significativo, y nos sirve como ejemplo de la invisibilidad que ha sufrido el trabajo de las mujeres a lo largo de la historia:

Que las mujeres sepan que forman parte de una tradición histórica como elaboradoras de elementos artísticos o simplemente materiales, es muy importante porque aporta la seguridad necesaria que proporciona el sentirse parte de una tradición, librándose así de la permanente sensación de «pionerismo» que deja a las mujeres huérfanas de genealogía femenina y de modelos o referentes (Bernárdez, Fernández, López Cao, s/f).

Quiero puntualizar que al decir «cerámica» no me quiero limitar exclusivamente a la alfarería, todo lo contrario, mi intención es visibilizar la variedad de producción cerámica y en especial la de cerámica contemporánea, la cual en numerosas ocasiones adquiere un carácter vinculado a otras disciplinas artísticas, como bien pueden ser la pintura o la escultura, (exenta de función utilitaria); no obstante la alfarería tiene un peso incuestionable en la historia de la cerámica y es por ello que me parece fundamental tenerla en cuenta para entender el contexto cerámico actual. Por otro lado, creo necesaria una perspectiva que amplíe la visión de lo artístico y en particular de lo que entendemos por cerámica contemporánea, incluyendo bajo este concepto a aquella que guarda una relación formal y conceptual con el tiempo en el que se vive, y en su caso, evitando que la relación con la alfarería sea un impedimento para tal consideración, de lo contrario, de nuevo estaremos manteniendo o generando jerarquías que no favorecen entre otras cuestiones la igualdad de género:

Es llamativo observar cómo la desvalorización de la obra artística y su conversión al rango de artesanía, y más concretamente de arte popular -como prefiere llamarle Ely Bartra- coincide muchas veces con la procedencia económica -es el arte de los pobres (Bartra, 1994, 15)- o la procedencia geográfica, el arte de los no occidentales. Se considera como alejado del arte de las élites no sólo aquel producido por mujeres, por esa subalteridad humana, sino aquella producción realizada por seres empobrecidos, segunda subalteridad, o por seres no occidentales, tercera subalteridad no ordinal (López F. Cao, s/f).

\section{Invisibilización. La escasa presencia cerámica en los espacios artísticos}

En todo caso, resulta un tanto complicado enlazar la historia de la cerámica ligada a la alfarería con la cerámica contemporánea a la cual pretendo prestar atención. Además de la tradición alfarera, hay otros factores a tomar en cuenta para poder explicar ese gran salto a la cerámica contemporánea, los cuales tienen que ver con los cambios que se dan en el 


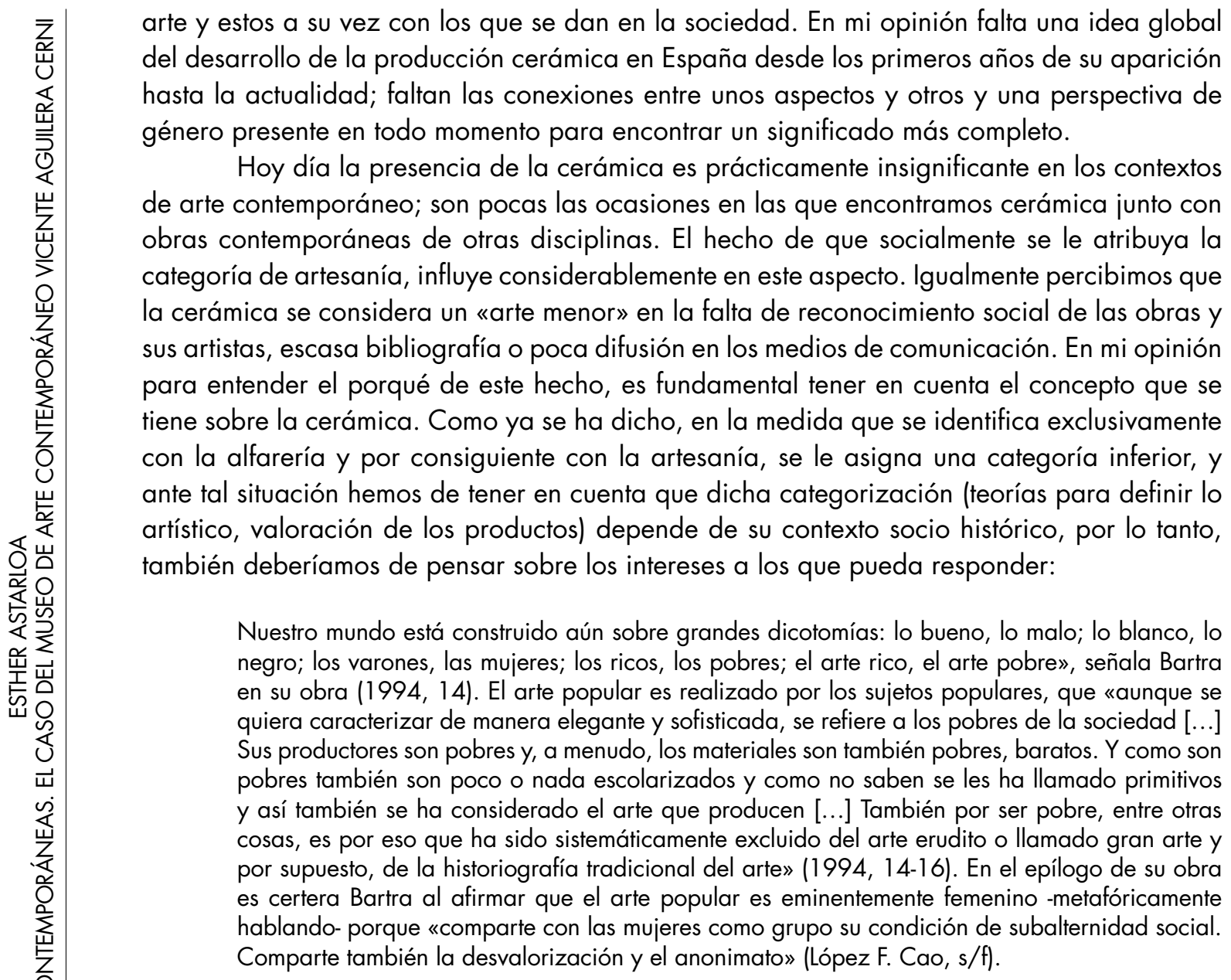

\section{Panorama actual, las/os ceramistas y sus obras}

En cuanto al panorama actual de la cerámica contemporánea en España, probablemente la última exposición más relevante como representativa de la misma haya sido «Fuera de Serie. De la provocación a la ilusión», celebrada en 2016 en el Museo Nacional de Cerámica González Martí, en el marco del Congreso Internacional de Cerámica (AIC) que tuvo lugar en Barcelona. 
Esta exposición fue comisariada por la experta en el tema Carmen González Borrás; para ella, haciéndose eco de un sentir generalizado por la nueva investigación del arte, ni la cerámica artística ni sus ceramistas ocupan el lugar que merecen:

Quizás podemos encontrar en ellos esa línea que define la cerámica de nuestro país, esas características propias que nos distinguen de otros. En pocos lugares la tradición es tan grande y abarca periodos tan grandes de la Historia como en España. Para los artistas que crecen con una tradición de ese calibre sólo hay dos posibles caminos: empaparse bien de la misma para actualizarla a su época, o escapar de ella y crear algo totalmente distinto. [...] Y lo han hecho muy bien, aunque en este país no tengan el reconocimiento que se merecen y deban debatirse cada día entre la desilusión y la supervivencia económica» (González Borrás: 2016: 3).

En esta muestra observamos la participación de veintiocho hombres y veintidós mujeres, lo cual en principio parece una representación bastante equitativa en lo que al género se refiere. Si además tenemos en cuenta que probablemente no ha habido ninguna política de igualdad que haya favorecido dicha equidad, yo diría que incluso la «elevada» representación femenina llega a llamarnos la atención. Sin embargo, si tenemos en cuenta la cantidad de mujeres que desarrollan estas prácticas en la cotidianeidad, en escuelas, talleres, ferias...constatamos que esta igualdad no es tal y que las diferencias de género siguen repercutiendo en este ámbito.

Anterior a esta exposición se han llevado a cabo otras de similares características, tratando de visibilizar la cerámica contemporánea de España, tales como «La cerámica española y su integración en el arte» (2006), «Escultura cerámica ibérica contemporánea» (2007) ○ «La cerámica española para el s. XXI» (2010). Todas ellas nos acercan al contexto actual. Son muchos los nombres de artistas que se repiten en estas muestras, por ejemplo Rosa Amorós, Madola, Arcadi Blasco, María Bofil, Elena Colmeiro, Ángel Garraza o Enric Mestre entre otros/as. Cabe decir que la representación femenina en el panorama más reciente se sitúa en torno a un $40 \%$ en las muestras señaladas. A estos acontecimientos tendríamos que añadir los concursos y ferias de cerámica contemporánea que se celebran periódicamente en diferentes lugares de la península y que exponen la obra cerámica más reciente.

Estos espacios a los que me he referido, son lugares exclusivamente cerámicos, y aquí se abre un interesante debate sobre si son positivos este tipo de eventos o si por el contrario ejercen una influencia negativa, apartando a la cerámica y por consiguiente a los artistas que a ella se dedican, de lo que es el panorama artístico general, no llegando nunca a permitir que forme parte del mismo. En mi opinión, en principio son positivos pues consiguen visibilizar y dar a conocer la cerámica, y esto es algo muy necesario. Ello no debiera 


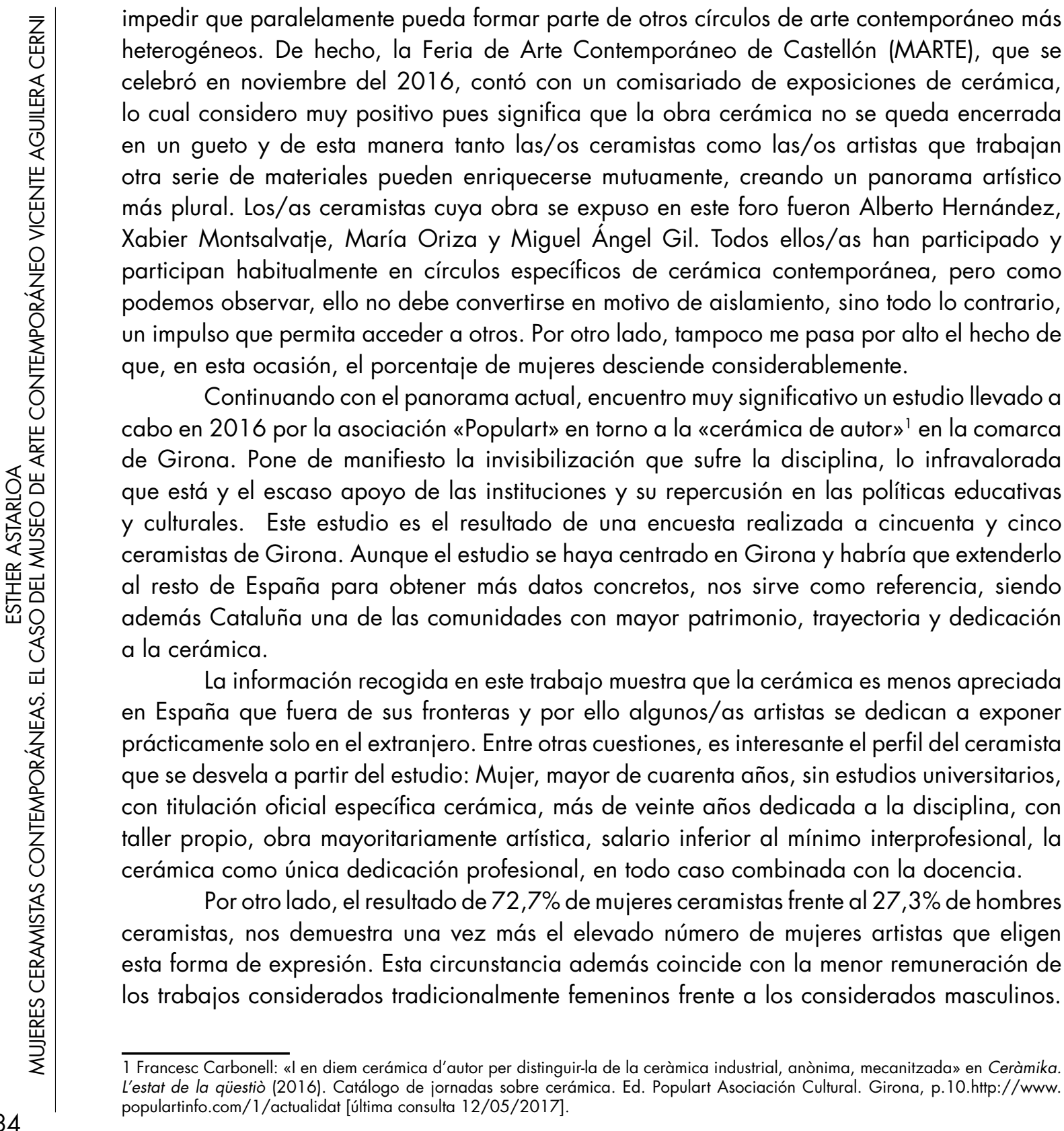

Dossiers Feministes, 23, 2018, 77-94 - ISSN: $1139-1219$ - DOI: http://dx.doi.org/10.6035/Dossiers.2018.23.5 
También nos confirma que el hecho de que en la «élite» de la disciplina cerámica encontremos un número de mujeres equiparable al de los hombres, se debe a que son muchas más las mujeres las que se dedican a la cerámica, lo que ocurre es que tal y como sucede en otras ramas, en la medida en que se va subiendo de cargo, categoría o responsabilidad el número de mujeres va descendiendo.

\section{El caso del Museo Vicente Aguilera Cerni de Vilafamés}

El caso del MACVAC me ha servido como punto de partida para llevar a cabo un estudio en torno a la cerámica contemporánea y la presencia de las mujeres ceramistas en la misma, para lo cual, me he centrado en analizar la obra y trayectoria de las/os ceramistas que alberga dicho museo. Este centro es una de las primeras instituciones dedicadas al arte contemporáneo en España. Alberga alrededor de 700 obras de arte cuyos artistas son referente de la vanguardia artística tanto a nivel nacional como internacional. Aunque en su colección la mayor parte de obras son de pintura, hay una gran representación de escultura y cerámica, razón por la cual he escogido dicho museo, pues esto es un hecho un tanto excepcional, ya que no suele ser habitual la presencia de cerámica en las colecciones de museos de arte contemporáneo. Sin embargo, el MACVAC cuenta con una colección de cerámica cuyos autores/as son algunos de los nombres de ceramistas contemporáneos/as más reconocidos a nivel nacional e internacional.

Después de revisar la colección del museo, he encontrado la obra de las/os siguientes diecinueve ceramistas: Angelina Alós, Arcadi Blasco, Cristina Cabrelles, Antonia Carbonell, Pilar Carpio, Norberto di Giorno, Víctor González, Marisa Herrón, Joan Llácer, Enric Mestre, Dolors Molina, Loretta Polgrossi, Carme Riu de Martín, Manuel Safont, Elisenda Sala, Carmen Sánchez Oroquieta, Mercedes Sebastián Nicolau, Nuria Torres y Dionisio Vacas Cuenca.

Como vemos, hay doce mujeres y siete hombres. Esto es, el $63 \%$ son mujeres. Este dato nos confirma la elevada presencia femenina en esta actividad, cosa que habíamos supuesto de antemano. Esta proporción contrasta con el $22 \%$ de mujeres artistas con las que cuenta la colección del MACVAC en su totalidad.

¿Por qué esta diferencia?

La respuesta a esta pregunta podemos hallarla en la relación cerámica-género que hemos observado anteriormente y en el sistema del arte actual. Por un lado, el hecho de que las mujeres hayan trabajado la cerámica desde muy atrás en el tiempo, hace que se sientan «en su terreno» lo cual favorece su participación en la disciplina. Por otro, los roles y espacios asignados a las mujeres en base al género, su entorno social, la política e incluso las leyes, 
durante largos años han favorecido que estas se hayan dedicado a la artesanía o a las denominadas artes menores (incluida la cerámica). Como ya se ha dicho, sigue patente en el sistema del arte actual la jerarquización que habitualmente excluye a las «artes menores» de los espacios representativos del arte contemporáneo, entre ellos los museos.

Esto explica la diferencia de la que hablamos. Es decir, cuando se da un cambio en el sistema, como es el caso del MACVAC, que incluye obra cerámica en su colección, sorprendentemente «aparece» un número relativamente alto de mujeres artistas. Esto nos hace recapacitar sobre el gran número de mujeres artistas que el propio sistema del arte invisibiliza.

Los trabajos que encontramos en el MACVAC coinciden en el exquisito conocimiento de la técnica de sus autores/as. No en vano forman parte de una generación de ceramistas que han tenido desde sus inicios contacto con la cerámica tradicional (punto en el que igualmente coinciden). Todos ellos han recibido formación específica y su dominio del material es excelente. Se podría decir que mientras muchos pintores o incluso escultores contemporáneos han desdeñado la técnica, no ha ocurrido lo mismo en el caso de los y las ceramistas, que siempre le han prestado mucha atención.

La constante investigación del material cerámico y sus numerosas posibilidades plásticas y estéticas, reafirman la cerámica como una disciplina específica cuya expresión artística es equiparable a cualquier disciplina en el mundo del arte. Las inquietudes de los autores/as que utilizan el lenguaje cerámico y sus planteamientos tanto estéticos como conceptuales (geometría, abstracción, informalismo, arte matérico, naturaleza, reivindicación social, minimal art, land art...) coinciden con las que hallamos en otros campos, reafirmando nuevamente la cerámica como disciplina artística.

Por otra parte, considero importante señalar que el MACVAC cuenta con una incorporación reciente (2017) de cerámica de diseño industrial que no incluimos aquí por tratarse de un discurso diferente. No obstante, y a simple vista, esta obra nos ofrece la posibilidad de contrastar algunos aspectos muy significativos: se trata de cinco piezas elaboradas en material cerámico, cuyos autores/as, en este caso cuatro hombres y una mujer, son diseñadores o artistas de reconocimiento internacional, lo cual repercute en gran medida en que su contexto y circunstancias sean absolutamente diferentes. Estas piezas «de diseño» se pueden encontrar en ferias, museos, tiendas, marcas importantes, revistas de moda... etc., probablemente porque sus diseñadores/as tienen gran prestigio y reconocimiento en el mercado y público especializado. En este caso observamos cómo el material pierde sus prejuicios y la obra «asciende de categoría». Nos percatamos de que cuando la obra cerámica sale de su «contexto cerámico» y habita otros espacios artísticos, no solo pierde la 
connotación de objeto artesano para ganar la de artístico, sino que además pierde autoría femenina en favor de la masculina. El elevado número de mujeres (en comparación a otras disciplinas) cuya obra es representativa de la cerámica contemporánea en España, también disminuye notablemente en los casos en los que esta obra cerámica pasa a formar parte de un panorama de arte contemporáneo más global.

Ante la imposibilidad de incluir en este artículo la información referente a todas/os las ceramistas presentes en el museo, he escogido presentar a Angelina Alós, por ser una de las pioneras de la cerámica contemporánea en España y por la necesidad de dar visibilidad a la obra de las mujeres mostrando su presencia significativa en el arte.

\section{Angelina Alós Tormo, ceramista contemporánea}

Angelina Alós nace en Valencia en 1917 y muere en Barcelona en 1997. Cuando contaba con tan solo un año su familia se desplaza a Barcelona al ganar su padre la plaza de profesor de cerámica en La Escola del Treball. De padre y abuelo ceramistas, toma contacto con este arte muy pronto, y a los 14 años ya realiza piezas en el taller paterno. Recibe clases de pintura, dibujo, escultura, modelado en yeso e historia del arte en la única escuela de cerámica de Barcelona (en la que trabaja su padre) y en la que posteriormente será profesora. La marginación que sufren las mujeres en los años 50 impide que, al jubilarse el profesor Rigal, director del departamento, ella tome su puesto; siendo Antoni Cumella, otro reconocido ceramista, quien lo ocupe.

Pese a haber asumido mucho más trabajo que sus compañeros masculinos con el objetivo de obtener una buena formación y poder ejercer dicho puesto, cuando por fin llega el momento en el que su profesionalidad le permite ser la persona idónea para ejercer un cargo directivo, la discriminación en base al género que sufren las mujeres, se lo impide definitivamente. «Fui un aprendiz muy poco protegido. Acarreé madera y carbón para cocer las muflas, tapé puertas de refractario y cargué de piezas las mismas (los hornos)» (Alós: 1982:60).

Sin embargo, mostrando gran iniciativa, valentía y seguridad en sí misma, Angelina Alós se marcha a Esplugues de Llobregat y crea su propia escuela taller.

Además de su original, amplia y variada obra, crea escuela, pues por sus clases pasan varias generaciones de ceramistas: Juli Bono, Lluis Castaldo, Magda Martí, Monserrat Sastre, Frederic Gisbert y Carles Ballester entre otros. El hecho de que ceramistas reconocidos como los mencionados sean sus discípulos constata los grandes conocimientos de Alós como ceramista. Que entre ellos haya tantos alumnos masculinos significa que incluso consigue que 
los prejuicios en base al género, queden en un segundo plano. Esto es muy importante, pues su ejemplo no responde al rol de mujer que la sociedad asigna y crea un nuevo precedente, cambiando conceptos que ayudarán a que las diferencias en base al género disminuyan. Además, es una figura presente en los mismos inicios de la cerámica contemporánea en España. En 1959 es nombrada miembro de la Academia Internacional de Cerámica.

Importantes críticos de arte como Vicente Aguilera Cerni se refieren a Angelina Alós como una de las grandes figuras de la cerámica en España; Manuel González Martí subraya su originalidad, elegancia y actualidad y Alexandre Cirici Pellicer encuentra en su cerámica una nueva expresión artística (Cifr. Aguilera Cerni: 1991: 28).

Realiza numerosos viajes de estudio a Europa y América. Le gusta la cerámica mediterránea, pero su interés se amplía, admira la sobriedad de los nórdicos y la impresión y la fuerza de la cerámica oriental. Su obra figura en museos especializados de Barcelona, Valencia, Italia, Suiza y Holanda y en colecciones particulares de Estados Unidos, Argentina, Perú, Venezuela, Panamá, Alemania, Gran Bretaña, Holanda, Francia, Italia, Japón y España.

Alós es una autora que conoce bien la técnica y los materiales cerámicos y se vale de ello para crear nuevas y variadas formas que rompen con la tradición cerámica. Gres con porcelana, con telas, con cúmulos de barniz, a veces con formas grotescas y abstractas, proporcionando al espectador un nuevo lenguaje. Su obra es diversa y compleja. Trabaja tanto piezas seriadas como pieza única, así como murales de grandes dimensiones destinados al espacio público. Ella concibe la cerámica como forma y color. Modela fuera del torno objetos escultóricos, piezas con luminosidad y colorido:

Mi obra significa la naturaleza. Me da idea la forma de una fruta, una roca, un trozo de tierra reseca, un cráter, una corteza de árbol, la fauna marina etc. Quizá es esto un camino fácil, puesto que la forma y el color están allí, sugiere lo infinito. No creo ser la única que recurra a esas ideas. No invento nada; este es el significado de la obra. [...] No pretendo que la obra se dirija a un determinado camino. Procuro hacerlo de la forma más sincera y honesta posible. Aun sintiéndolo no veo que mi obra se dirija a un vanguardismo en extremo (Alós: 1982: 61).

Es importante citar los aspectos más técnicos de su trabajo relacionados con los diferentes materiales, resultado de sus constantes investigaciones que en muchos casos han revolucionado la cerámica contemporánea.

Su extensa producción se podría clasificar a partir de las diferentes maneras de abordar las piezas cerámicas: a través de jarros deformes, naturalezas muertas y representaciones de figuras de animales o simbólicas, placas y grandes murales de texturas rugosas y, finalmente, platos enlazados o montados en un pedestal a modo de frutero. 
A continuación, vamos a referirnos a las dos piezas que Angelina Alós tiene en el MACVAC. La primera (Fig. 1) es una original cerámica esmaltada de carácter abstracto y formas orgánicas. Son protagonistas el color y textura brillante de los esmaltes aplicados sobre la pieza cerámica, con cuya aplicación se ha pretendido conseguir una especie de «manchas naturales» donde no se perciba la mano del artista (sin dibujar o pintar). Este tratamiento de la superficie, refuerza la abstracción de la pieza y la importancia de lo matérico del propio esmalte; podemos decir que es una pieza que se encuentra en la vía del informalismo.

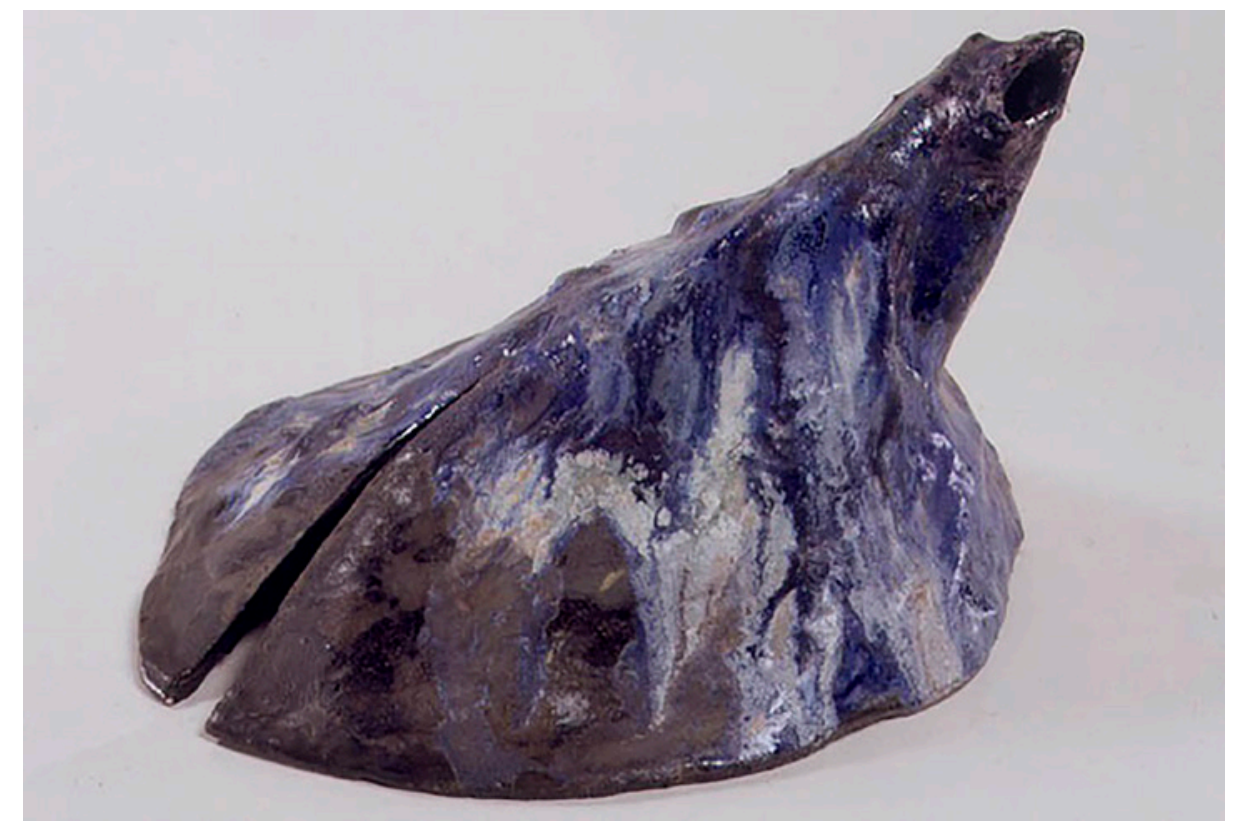

Fig. 1. Angelina Alós, Cuerno de la abundancia, s/f. Cerámica esmaltada, $25 \times 43 \times 43 \mathrm{~cm}$. Fuente: Centro Internacional de Documentacion Artística (CIDA) Vilafamés.

La segunda de las piezas de Alós en el Museo (Fig. 2) es una obra sin título. Se aprecia un plato cuya forma se ha manipulado de tal manera que ha perdido su funcionalidad y se ha convertido en una pieza prácticamente abstracta. Cobran protagonismo las texturas y la propia materia cerámica. Los colores (probablemente óxidos y engobes) han sido aplicados a modo de mancha, gestual, también relacionada con el informalismo. 


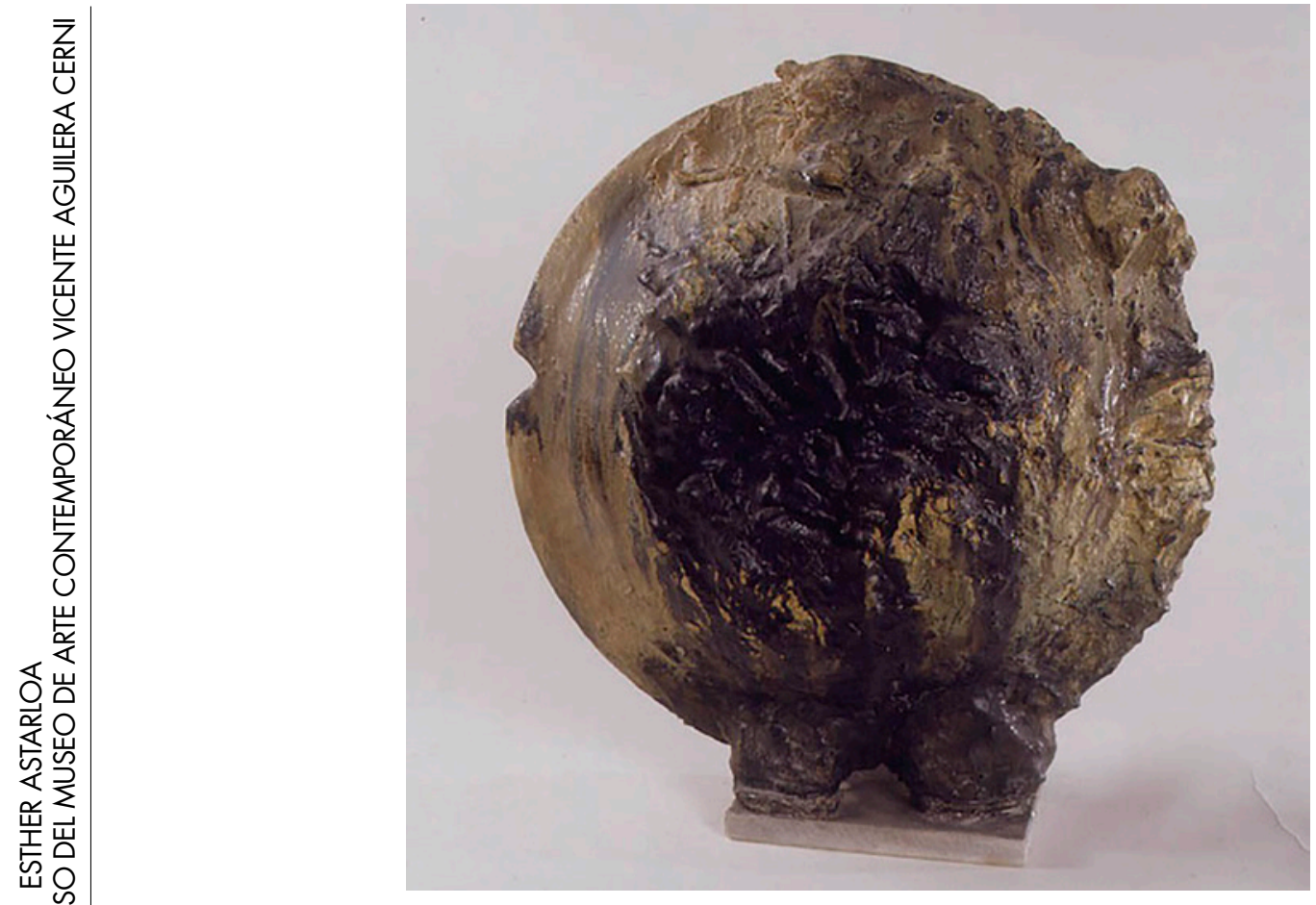

Fig.2. Angelina Alós, S/T, s/f. Cerámica, $48 \times 48 \times 20 \mathrm{~cm}$. Fuente: Centro Internacional de Documentacion Artística (CIDA) Vilafamés.

En ambas piezas observamos cierta relación con la idea de lo femenino: en la primera el cuerno de la abundancia (cornucopia). En la mitología griega, la cabra Amaltea amamanta a Zeus. Este, mientras está jugando, sin querer rompe uno de los cuernos de la cabra. Para compensar a Amaltea, al cuerno roto se le confiere el poder de conceder todos los deseos. De ahí surge la leyenda de la cornucopia. Este símbolo de abundancia y prosperidad parte de una idea relacionada a la maternidad, que a su vez es uno de los roles más importantes de lo considerado femenino. Mi lectura personal sobre esta obra es la importancia que ella le confiere a sus inquietudes, sus objetivos, al fin y al cabo, a conseguir sus deseos (que probablemente no coinciden con los que la sociedad le ha asignado por el hecho de ser mujer).

En la segunda pieza, la artista ha escogido como motivo un plato, objeto cotidiano, relacionado al hogar, a la alimentación y cuidado de la familia, por tanto, un objeto 
históricamente relacionado a la mujer. Aunque en este caso, la artista se vale del mismo para desarrollar su creatividad e inquietud artística y el plato pierde su funcionalidad como tal. Alós desafía el uso «correcto» y «legítimo» de la arcilla, liberando a los platos y jarrones de su funcionalidad y dotándolos de una nueva simbología. Personalmente opino que esta actitud artística también muestra una actitud feminista, en cuanto a que rompe con los roles establecidos en el tratamiento y significado de la obra y también en su actitud como mujer artista que decide crear algo nuevo, fuera de la tradición; mostrando que el arte se da, independientemente de si el sistema lo considera arte o no.

En mi opinión, ninguno de los dos motivos está escogido de forma casual. Observo en ellos un deseo de reivindicar lo considerado femenino a la vez que de transformarlo.

\section{Conclusiones}

Tras realizar este estudio, una de las primeras conclusiones que obtenemos es que, en el contexto de la cerámica contemporánea en España, el género juega un papel importante. La catalogación del producto (artesano o artístico) influye en el prestigio que se le atribuye a su autor/a y viceversa, es decir, la autoría también interviene en la catalogación y prestigio del producto; en este caso consideramos que todavía se asocia más fácilmente la artesanía a las mujeres y el arte a los hombres. No obstante, el análisis de la cerámica contemporánea que alberga el MACVAC nos permite observar que la obra de hombres y mujeres artistas se asemejan en capacidad técnica, conceptual y creativa. Sus obras reflejan las inquietudes, pensamientos o sentimientos del autor/a, acordes a la realidad social y a las corrientes artísticas de su tiempo. En este sentido, prácticamente no encontramos sesgos de género que nos revelen si su autoría es masculina o femenina y ello elimina ciertos prejuicios que pudieran existir respecto a un «arte masculino» que se diferenciara de un «arte femenino».

A su vez nos percatamos de que cuando la obra cerámica sale de su contexto exclusivamente cerámico y habita otros espacios artísticos no solo pierde la connotación de objeto artesano para ganar la de artístico, sino que además pierde autoría femenina en favor de la masculina.

Por tanto, encontramos la necesidad de visibilizar y valorar la obra cerámica en general y la de las mujeres artistas en particular. En primer lugar, me parece muy importante que sean las propias ceramistas quienes renueven su mirada hacia sí mismas y hacia su obra y que ello les aporte la autoestima necesaria para querer mostrarse, empoderarse y reivindicar sin complejos su lugar en el campo artístico. Por supuesto también es necesario que el entorno (artistas, galeristas, críticos de arte, museos, docentes, medios de comunicación, público en 


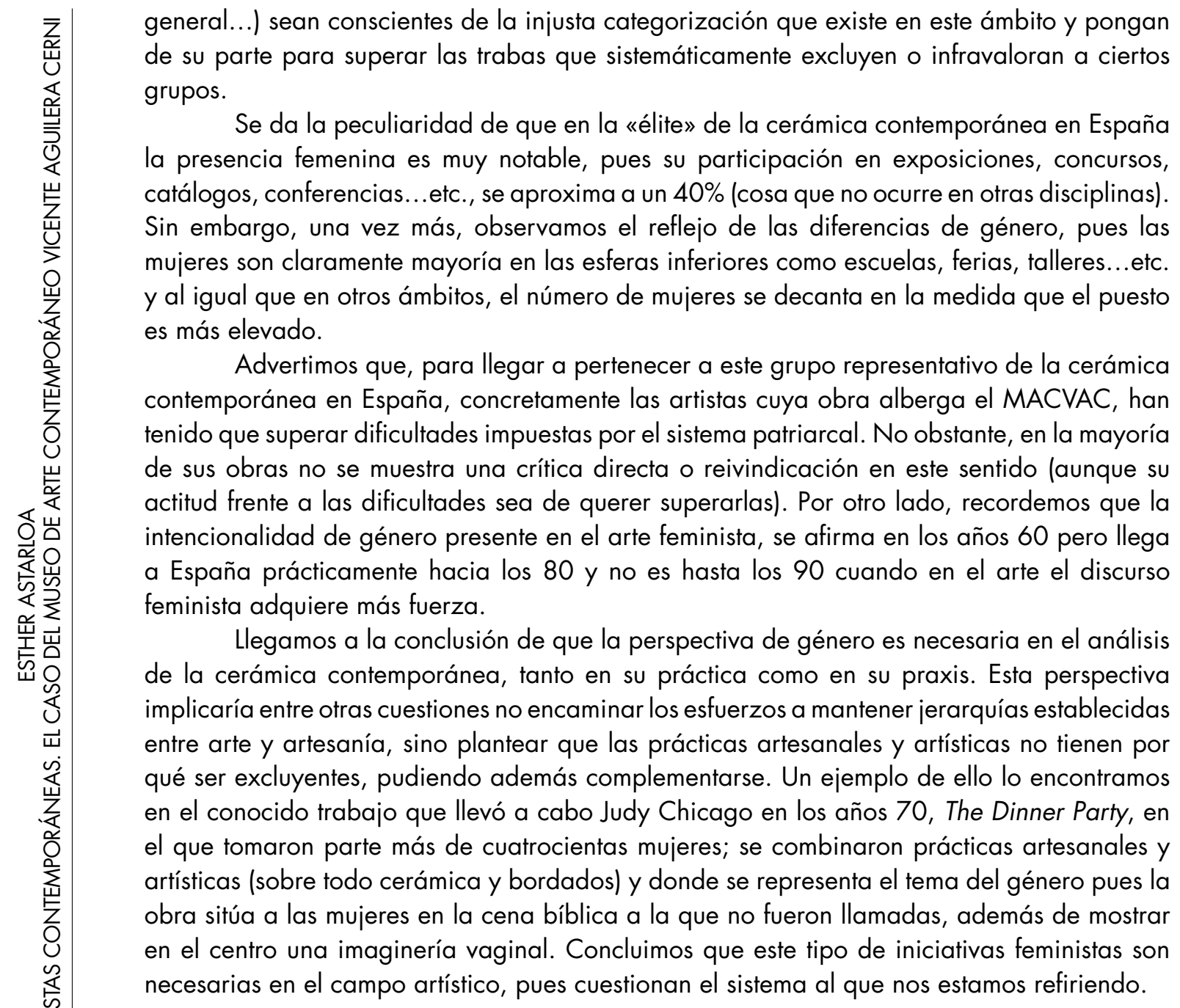

\section{Referencias bibliográficas}

Aguilera Cerni, Vicente (1991). «La cerámica de Angelina Alós», en Batik: Panorama General, $N^{\circ} .105$, p. 28. 
Alba Calzado, Miguel y María Jesús Fernández García (1993). «La participación femenina en la cerámica extremeña» en Coloquios Históricos de Extremadura. Extremadura: Asociación cultural Coloquios Históricos de Extremadura. pp. 1 - 7 http://www. chdetrujillo.com/tag/miguel-alba-calzado-y-ma-jesus-fernandez-garcia/

Alós Tormo, Angelina (1982). «Angelina Alós» (entrevista) en Revista Cerámica, №. 12, pp. 60- 63.

Bernárdez, Asunción; Fernández Antonia y Marián López F. CaO (s/f). «La vida de las mujeres a través de la cerámica y las artes santuarias», en Didáctica 2.0 museos en femenino, Museo Nacional de Cerámica González Martí. Valencia. www.museosenfemenio.es

GonZÁlez BorRÁs, Carmen (2016). «Fuera de serie. De la provocación a la ilusión» en Catálogo de la exposición temporal, del 21 de julio al 2 de octubre de 2016, Valencia: Museo Nacional de Cerámica González Martí.

LÓPEZ F. CAO, Marián (sin fecha). «Metodologías para la investigación sobre arte y género: Una propuesta posible» en Revista digital universitaria Madrid: Universidad Complutense de Madrid.

Disponible en: http://pendientedemigracion.ucm.es/info/arte2o/documentos/investigacionmarian.htm

RICE, Prudence (1999). «Mujeres y Producción Cerámica en la Prehistoria» en Colomer, Laia; González Marcén; Paloma, Montón, Sandra y Marina Picazo (comps.) (1999). Arqueología y teoría feminista. Estudios sobre mujeres y cultura material en arqueología, Barcelona: Icaria.

SCHÜтZ, Ilse (1993). La mujer en la alfarería española. Simposio de Investigación Cerámica y Alfarera. Agost: Colegio Oficial de arquitectos de Alicante. Ed: Centro Agost Museo de Alfarería.

YePES SANCHIDRIÁN, María Victoria (1987). «Mujeres alfareras: algunos aspectos de la alfarería femenina en España» en VvAA, Etnología y tradiciones populares: (Congreso de Zaragoza - Calatayud). España: Ed. Institución Fernando el Católico.

VvAa (2016). Ceràmika, L'estat de la qüestió, Girona: Ed. Populart Asociación Cultural

\subsection{Webgrafía}

WEB COMPLETA: MACVAC, museu d'art contemporani Vicente Aguilera Cerni, Vilafamés. Disponible en http://macvac.vilafames.es/ (Fecha de consulta: 5/12/17) 


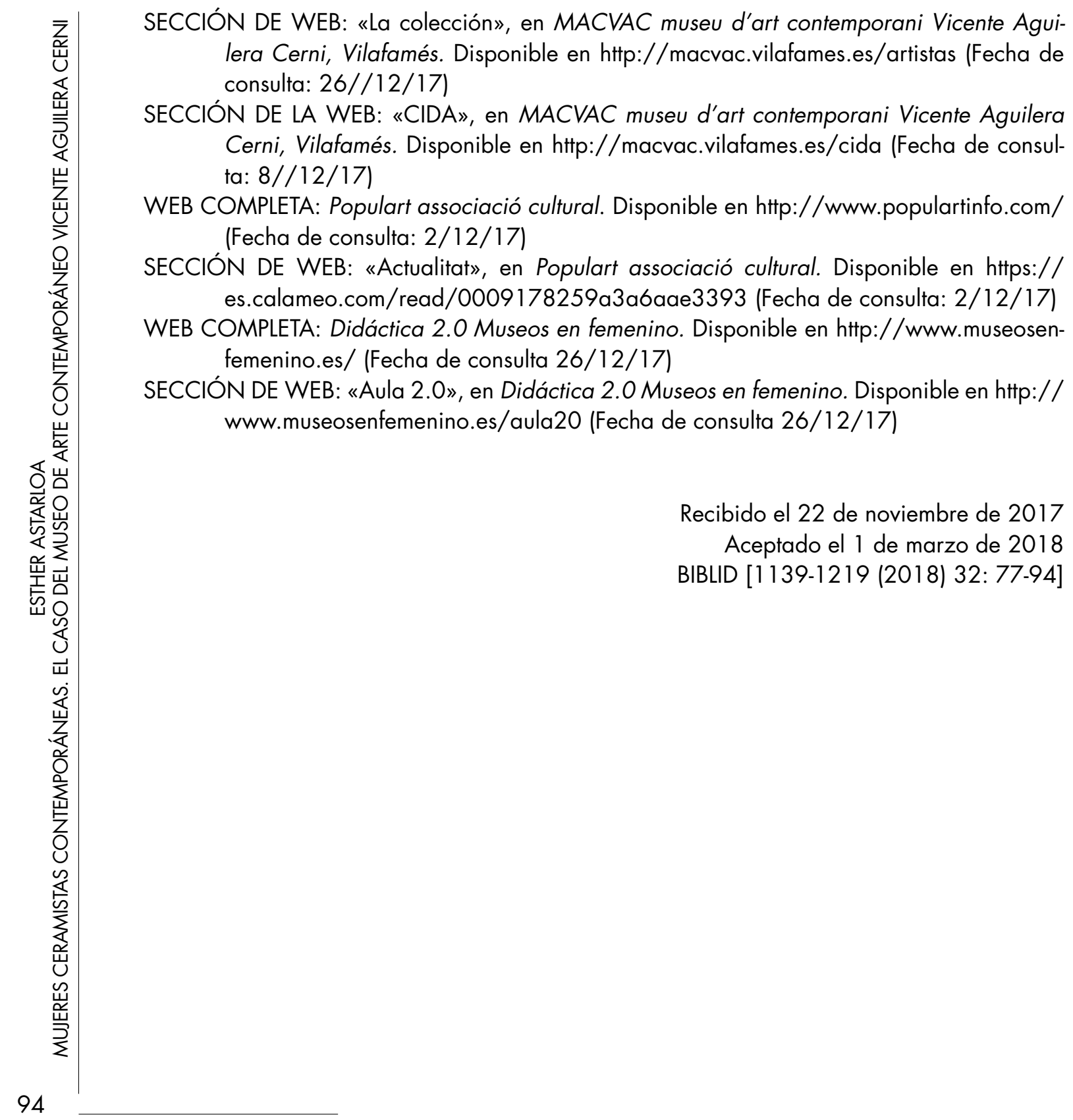

Dossiers Feministes, 23, 2018, 77-94 - ISSN: $1139-1219$ - DOI: http://dx.doi.org/10.6035/Dossiers.2018.23.5 